\title{
Scale effect of viticultural zoning under three contrasting vintages in Chianti Classico area (Tuscany, Italy)
}

\author{
Simone Priori ${ }^{*}{ }^{*}$, Giuseppe Valboa ${ }^{1}$, Sergio Pellegrini ${ }^{1}$, Rita Perria $^{2}$, Sergio Puccioni ${ }^{2}$, Paolo Storchi ${ }^{2}$, Edoardo A.C. \\ Costantini ${ }^{1}$ \\ ${ }^{1}$ CREA Research Centre for Agriculture and Environment, Cascine del Riccio, Firenze, Italy. \\ ${ }^{2}$ CREA Research Centre for Viticulture and Enology, Arezzo, Italy \\ *corresponding author email: simone.priori@crea.gov.it
}

\begin{abstract}
The present study, performed in one of the largest farm of "Chianti Classico" wine district (Tuscany, Italy), focused on the effect of terroir on the peculiarities of the wine at two different scale of zoning. At a broader scale, the experimental vineyards were selected on the basis of lithology, soil type, morphology and climate and these were called macro-terroir (MT). Each vineyard was subdivided into a couple of homogeneous zones (Unité Terroir de Base, UTB), differentiated on the basis of soil proximal sensing, and then, high-detailed soil mapping. The study was conducted during three consecutive vintages (2012, '13 and '14), on four different vineyards MT, which are representative of the Chianti Classico wine district. Grape harvest, wine-making and six-month ageing were carried out separately for each UTB, using the same methodology. This study demonstrates that characteristics of geopedological landscapes can be used for a wine district zoning, while a more detailed soil mapping, leading to UTB identification, is needed to highlight some wine peculiarities.
\end{abstract}

\section{Introduction}

Lithology and soil spatial variability is usually very high in most of the Italian viticultural areas. This variability can provide distinctive peculiarities to the wines, not only within a single wine district, but also within a single farm and a single vineyard. Recent approaches in managing spatial variability in vineyards are based on high resolution mapping of homogeneous vineyard zones. These basic units are used to plan differentiated vineyard management and grape harvest, in order to highlight the terroir effect on wine $[1,2,3]$.

Several studies have addressed the terroir effect on wine on the basis of grape analysis and micro winemaking experiments within small vineyard plots $[4,5]$. This approach allows to study the relationships between grape, vine and soil features accurately, however it does not answer the following questions [6]:

i) does variation of soil properties have a functional impact on wine peculiarities?

ii) if so, at what scale are these effects expressed (Between vineyards, within vineyard)?

The present study was performed in a large farm of the "Chianti Classico" wine district (Barone Ricasoli farm, Tuscany, Italy), with the aim to analyse the effect of terroir on the peculiarities of the wine, at two different zoning scales. At broader scale, four experimental vineyards were selected according to lithology, soil type, morphology and climate ("MacroTerroirs", MT). At finer scale, each vineyard was subdivided into couples of homogeneous zones, differentiated on the basis of soil proximal sensing data, and then soil features like texture, gravel content, soil depth, and available water capacity (Basic Terroir Units or Unité Terroir de Base, UTB, [7]). The four macroterroirs selected were highly representative of the Chianti Classico district. The grape from the different UTBs was harvested and processed for wine-making separately, following the same procedures.

\section{Materials and methods}

The vineyards studied for this work belong to Barone Ricasoli estate, a large and old farm in the Chianti Classico wine district, Tuscany. The farm embraces the four main geological units of the Chianti Classico district, which are: i) shales, marls and limestones (STO), covered by a thick layer of feldspathic sandstone (MAC), which represent the upper part of Tuscan geological unit, generally situated on the top of the hills (400-600 m a.s.l.); ii) limestone and shales of the Monte Morello formation (MLL), a Ligurian geological unit, situated on the top of the hills or along the slopes of the hills (300-500 m a.s.l.); iii) marine deposits of the Pliocene period (PLIs), and iv) deposits of fluvial terraces (AT) on marls and shales of the Sillano formation (SIL), both situated beneath 300$350 \mathrm{~m}$ a.s.l.

In this work, we defined as "macro-terroir" (MT) a large area characterized by the same lithology, morphology and climate, whereas we defined as "basic terroir units" (or Unité Terroir de Base, UTB [7]) subareas within a MT of about 2 ha in size, characterized 
by homogenous soil features (texture, stoniness, soil depth, available water capacity, etc.).

The four MT (Fig.1), representative of the four main lithology described above, were selected:

- SAND: sandy and gravelly soils on feldspathic sandstone, calcium carbonate free $(<1 \%)$.

- CALC: clayey and gravelly soils on limestone and shales, with high calcium carbonate content $(>25 \%)$.

- MAR: loamy soils on marine deposits, characterized by gravel lenses and moderate calcium carbonate content (10-20\%).

- FLUV: loamy and gravelly soils on ancient fluvial terraces, with variable calcium carbonate content (10-30\%).

The study was carried out in 12-16 years old Sangiovese $c v$. vineyards, the vine density varies between 6200 and 6600 vines/ha, and the trellis system was the simple spurred cordon with vertical shoot. The experimental vineyards received the same viticultural treatments during the growing season.

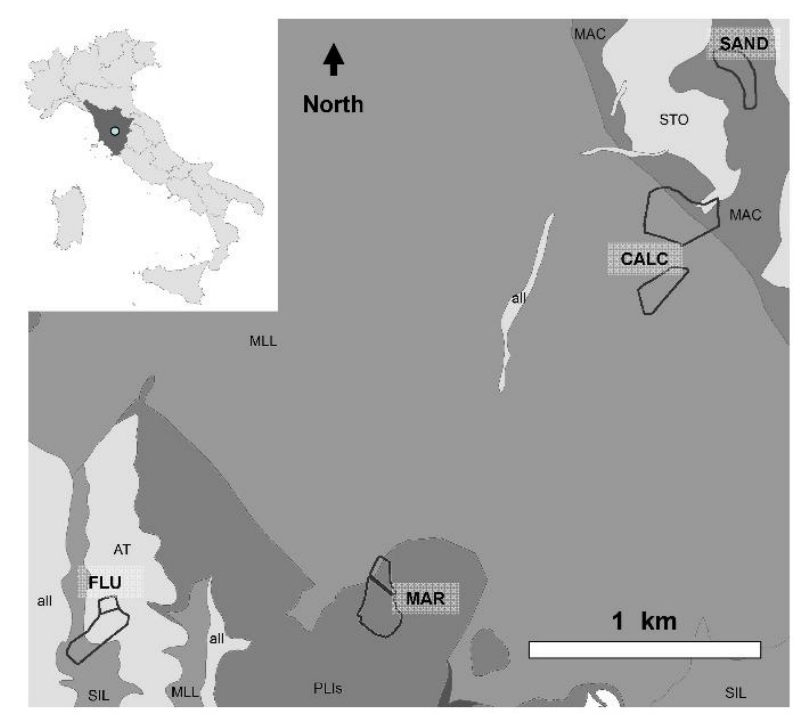

Figure 1: Experimental vineyards and geological formation. MAC: sandstone; STO: shales, marls and limestone; MLL: limestone and shales; PLIs: marine sandy and gravelly deposits; AT: ancient fluvial terraces; SIL: marls and shales; all: recent alluvial deposits.

The vineyards were surveyed by proximal sensing in order to obtain high-detail maps of soil spatial variability and to delimit the UTBs. The proximal sensors used were: i) EM38-Mk2 electromagnetic induction sensor (Geonics Ltd., Ontario, Canada) and ii) "The Mole", a gamma-ray spectroradiometer (Soil Company, The Netherlands). The EM38-Mk2 measures the soil apparent electrical conductivity (ECa) across two depth ranges of $0-75\left(\mathrm{ECa}_{1}\right)$ and $0-150 \mathrm{~cm}\left(\mathrm{ECa}_{2}\right)$, approximately [8]. "The Mole" spectroradiometer measures continuously the gamma-ray natural emission (total count, TC) coming from the first $30-40 \mathrm{~cm}$ of the soil and rocks, through a Cesium Iodide scintillator crystal [9]. Two UTB within each MT were delimited according to the k-means clustering. The variables used for clustering were: apparent electrical conductivity ECa1 and ECa2; total count of gamma-ray (TC); slope and aspect obtained by a digital elevation model with a detail of $10 \mathrm{~m}$.

Each MT was subdivided into two 1.5-2 ha size UTBs, for a total of 8 UTBs. Small areas with deep and too fertile soils, or subject to waterlogging or exceptional soil erosion, were excluded. The grape from each UTB was harvested and vinified separately, using the same methods. The grape must was analysed to determine sugar content, $\mathrm{pH}$ and malic acid concentration. Seven months after harvesting, the wines were analysed to assess the alcohol content, total polyphenols and anthocyanins, total acidity, dry extract, glycerine, and colour intensity.

Moreover, the wines were evaluated by a panel of 10 wine tasters through a "blind tasting". Sensory evaluation was performed to assess differences between the wines, therefore the evaluation method was mainly comparative. In particular, the wines were scored on a scale of 1 to 10 for each sensory attribute, giving the score 10 to the wine which expressed better than the others such parameter. The sensory parameters analysed were: overall evaluation, body, acidity, flavour intensity. In addition, the tasters indicated their feeling about the wine in terms of aroma typology: fruity, floral, spicy, and herbaceous.

In order to verify the interactions between vintage, MT, and UTB on wine peculiarities, a mixed design models were adopted, using vintage as random factor, MT as fixed factor and UTB nested in MT (hierarchical nested ANOVA).

\section{Results and discussion}

\subsection{Climate and terroir}

The climatic conditions were very variable during the three experimental vintages (Fig.2). In particular, 2012 showed the highest temperature (above the average) and a very dry summer, with some heavy rains two weeks before the harvest. In summer 2013, the temperature and rain trends were in line with the longterm averages, whereas summer 2014 was colder and more humid than the average. The modified Winkler index $\left(1^{\text {st }}\right.$ April $-30^{\text {th }}$ September $)$ was higher in CALC and SAND, than in MAR and FLUV (Tab.1).

Among the selected UTBs, CALC1 and 2 showed the highest content of clay, gravel, and calcium carbonate, along with the lowest gamma-ray $\mathrm{TC}$ and moderately high ECa. They significantly differed from each other only for the sand content, which is slightly higher in CALC2. The macro-terroir SAND was characterized by low ECa and high gamma-ray TC, because of the parent material mineralogy rich in kfeldspars and muscovite, which have high content of potassium, and then ${ }^{40} \mathrm{~K}$ radionuclide. Soils were sandy and calcium carbonate free. SAND2 showed higher stoniness and lower AWC than SAND1. MAR1 and 2 showed good differentiation in terms of $\mathrm{ECa}$, gamma- 
ray TC and soil features. In particular, MAR1 showed higher clay content, calcium carbonate and AWC, as well as lower stoniness, than MAR2.

Both FLUV1 and FLUV2 had clay-loamy texture, but FLUV2 showed higher content of sand, gravel and calcium carbonate.
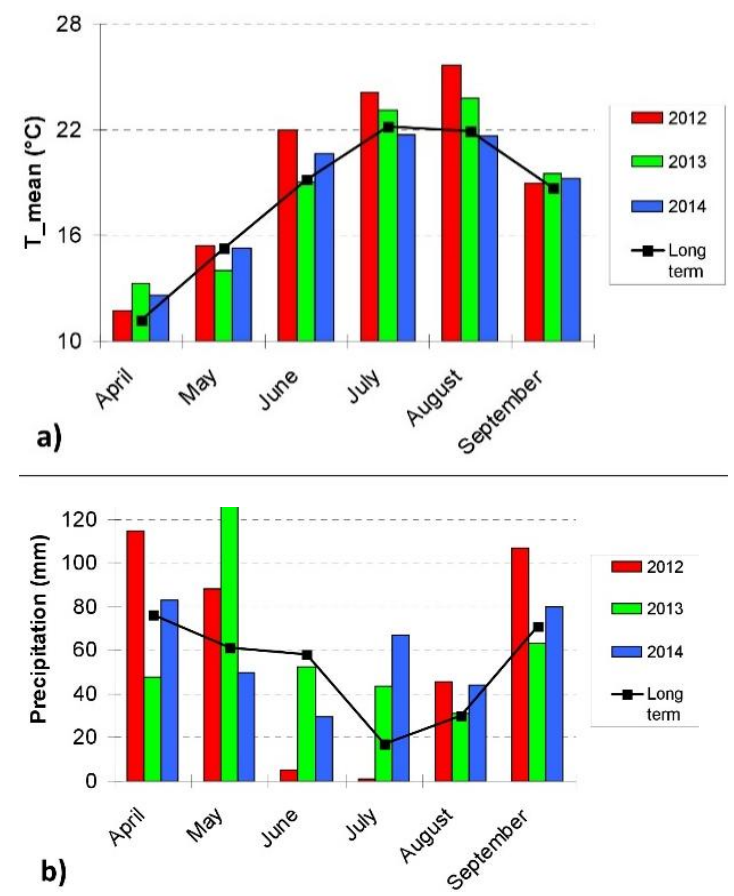

Figure 2: Mean air temperature and precipitation during the three growing seasons.

Table 1: Main features of the UTB. 1: modified Winkler index (calculated between $1^{\text {st }}$ of April and $30^{\text {th }}$ September); 2 : total calcium carbonate; 3: Available Water Capacity.

\begin{tabular}{|c|c|c|c|c|c|c|c|c|c|}
\hline UTB & $\begin{array}{c}\mathrm{WI}_{\text {mod }}{ }^{1} \\
\Sigma^{\circ} \mathrm{C}\end{array}$ & $\begin{array}{r}\mathbf{E C a}_{1} \\
(\mathrm{mS}\end{array}$ & $\begin{array}{l}\mathrm{ECa}_{2} \\
\left.\mathrm{~m}^{-1}\right)\end{array}$ & $\begin{array}{c}\mathrm{TC} \\
\left(\mathrm{Bq} \cdot \mathrm{kg}^{-1}\right)\end{array}$ & Clay & $\begin{array}{r}\text { Sand } \\
(\mathrm{g} \cdot 100\end{array}$ & $\begin{array}{l}\mathrm{CaCO}_{3}{ }^{2} \\
\left.{ }^{-1}\right)\end{array}$ & $\begin{array}{l}\text { Gravel } \\
\left(\mathrm{m}^{2} \cdot \mathrm{m}^{-2}\right)\end{array}$ & $\begin{array}{c}\mathrm{AWC}^{3} \\
\left(\mathrm{~mm} \cdot \mathrm{m}^{-1}\right)\end{array}$ \\
\hline CALC1 & & 20.4 & 28.2 & 317 & 36.0 & 16.5 & 25.1 & 30.8 & 114 \\
\hline CALC2 & 1737 & 21.7 & 25.8 & 318 & 33.6 & 21.6 & 33.9 & 36.2 & 94 \\
\hline SAND1 & 1730 & 8.2 & 12.1 & 669 & 9.8 & 59.8 & 0.4 & 19.2 & 113 \\
\hline SAND2 & $1 / 30$ & 5.7 & 11.2 & 666 & 10.0 & 61.0 & 0.2 & 36.5 & 64 \\
\hline MAR1 & 1613 & 32.9 & 31.0 & 410 & 35.3 & 33.5 & 27.7 & 8.1 & 139 \\
\hline MAR2 & 1613 & 23.4 & 23.4 & 358 & 19.2 & 51.3 & 16.5 & 21.8 & 103 \\
\hline FLUV1 & 1536 & 22.5 & 28.3 & 443 & 31.5 & 31.4 & 8.5 & 7.0 & 79 \\
\hline FLUV2 & 1536 & 19.0 & 25.6 & 404 & 25.5 & 39.8 & 15.6 & 27.2 & 67 \\
\hline
\end{tabular}

\subsection{Oenological results}

The contrasting climatic conditions that occurred during between the three experimental years determined vintage-to-vintage differences in the grape and wine quality. The coldest and most humid summer of 2014 provided poor differentiations between wines, hiding the terroir effect. On the contrary, during the warmest and driest summer of 2012, the wines from the eight UTBs showed the clearest differences. The results of mixed-design ANOVA, performed with MT as fixed effect, vintage as random effect and UTB nested in MT (tab.2), showed that:
- The variability in must $\mathrm{pH}$, wine total acidity, glycerine and colour intensity was explained better by the MT than the vintage climate, but the colour intensity was strongly dependent from the interaction between MT and vintage.

- Must malic acid, wine polyphenols, anthocyanins and dry extract were more influenced by the vintage climate, although the effect of the MT and the interaction MT $\mathrm{x}$ vintage played an important role. Vintage climate also affected the herbaceous and spicy notes in the wine flavor.

- In general, the effect of the UTB seemed important for differentiation of wine colour intensity, as well as for flavor intensity and fruity notes.

Changing the zoning scale from MT to UTB according to soil physical and hydrological properties, appeared to have a significant effect only under dry summers, like in 2012 and, to a less extent, in 2013.

Table 2: Fischer's F-values resulting from the mixeddesign ANOVA, using MT effect as fixed factor, vintage effect as random factor, and UTB nested in MT. In bold, Fvalues significant for $\mathrm{p}<0.05$.

\begin{tabular}{lcccc}
\hline $\begin{array}{l}\text { Source of } \\
\text { variance }\end{array}$ & MT & Vintage & $\begin{array}{c}\text { MT } \mathbf{x} \\
\text { vintage }\end{array}$ & $\begin{array}{c}\text { UTB } \\
\text { (MT) }\end{array}$ \\
\hline Must & & & & \\
\hline Sugar & 1.5 & 0.4 & 1.7 & 1.2 \\
pH & $\mathbf{5 . 1}$ & 2.5 & 2.4 & 1.2 \\
Malic acid & $\mathbf{9 . 6}$ & $\mathbf{6 1 . 3}$ & $\mathbf{4 . 3}$ & 2.7 \\
\hline Wine & & & & \\
\hline Total acid. & $\mathbf{5 . 1}$ & 4.8 & 2.2 & 1.9 \\
Polyphenols & $\mathbf{8 . 4}$ & $\mathbf{4 1 . 0}$ & 1.1 & 1.5 \\
Anthocyanins & 2.3 & $\mathbf{6 . 6}$ & 3.5 & 0.7 \\
Dry extract & 1.5 & $\mathbf{5 . 2}$ & $\mathbf{4 . 6}$ & 0.8 \\
Glycerine & 3.3 & 0.5 & 1.9 & 0.7 \\
Colour int. & 3.7 & 0.1 & $\mathbf{2 3 . 4}$ & $\mathbf{1 3 . 1}$ \\
\hline Wine taste & & & & \\
\hline Flavour int. & 0.1 & 2.4 & $\mathbf{2 . 4}$ & $\mathbf{3 . 3}$ \\
Fruity & 1.4 & 1.3 & 1.6 & $\mathbf{3 . 5}$ \\
Floral & 0.1 & 0.6 & $\mathbf{2 . 5}$ & 1.3 \\
Herbaceous & 0.2 & $\mathbf{2 0 . 3}$ & 0.5 & 2.2 \\
Spicy & 0.9 & $\mathbf{1 4 . 7}$ & 0.5 & 0.7 \\
Body & 0.3 & 1.0 & $\mathbf{5 . 5}$ & 0.6 \\
Acidity & 1.9 & 3.3 & 2.0 & 0.8 \\
\hline & & & &
\end{tabular}

In general, the wines produced in CALC macroterroir showed higher alcohol, anthocyanins, dry extract and colour intensity than the average, as well as high fruity flavor, high acidity and body. Similar results were reported in previous studies of the authors $[2,10]$. In particular, Ricci Alunni [11] observed high alcohol and colour intensity as distinctive features of wines produced on calcareous-clayey soil. On the contrary, the wines from SAND were characterized by lower colour intensity and lower acidity than the average, especially 
in the SAND2 UTB (higher stoniness and lower AWC), where however the flavor intensity was always high, in particular for fruity notes. This results are consistent with those reported by Ricci Alunni [11], who described the wines from sandy non-calcareous soils as elegant, scented, but scarce in colour. The lower acidity of these wines can be explained by the very low content of calcium carbonate and the high content of potassium in the soil, which tend to increase must and wine $\mathrm{pH}$ [12].

The wines produced on marine loamy sands (MAR) provide wines with low (MAR1) or medium (MAR2) alcohol and low glycerine. Moreover, MAR2, characterized by a soil with higher sand and gravel contents, provided wines with general higher flavor intensity, in particular fruity and floral notes. The differentiation between MAR1 and MAR2 was particularly evident in the driest summer of 2012, whereas it disappeared in the vintage 2014 .

The wines produced on fluvial terraces (FLUV) showed higher alcohol content, polyphenols and glycerine concentrations, especially in FLUV1, characterized by higher soil AWC and lower gravel. This confirms the results from a previous viticultural zoning work in the Siena province [10], showing higher alcohol and polyphenols values on fluvial terraces than in the other terroirs of the province.
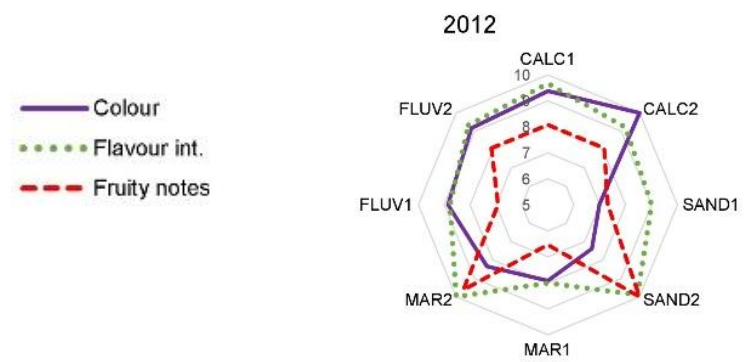

Figure 3: Spider graphs reporting the means (10 tasters) of the most significant wine tasting parameters (colour, flavour intensity, and fruity notes) for each UTB in the three vintages.
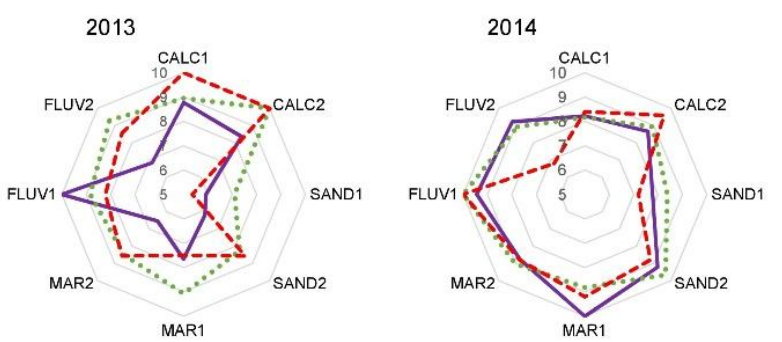

This work was supported by the "Barone Ricasoli" s.p.a. farm (VignaCRU project). The authors wish to thank the agricultural manager of the farm Massimiliano Biagi and co-workers (Fabio Cascella, Marco Cerqua, and Claudio Carapelli) for their support. Many other peoples contributed to the VignaCRU project and to this work, in particular we want to thank Pierluigi Bucelli, Nadia Vignozzi, Stefano Mocali, Arturo Fabiani, Romina Lorenzetti, Maria Fantappiè, Giovanni L'Abate, Roberto Barbetti, and Nadia Bianconi, Alessandra Zombardo and Marco Leprini, Aldo Ciambotti and Valentina Dell'Oro.

\section{References}

1. R. G. V. Bramley, J. Ouzman, P. K. Boss, AUST J GRAPE WINE R, 17(2), 217-229 (2011).

2. S. Priori, E. Martini, M.C. Andrenelli, S. Magini, A.E. Agnelli, P. Bucelli, M. Biagi, S. Pellegrini, E.A.C. Costantini, SOIL SCI SOC AM J, 77(4), 1338-1348, (2013).

3. J. Tardaguila, M.P. Diago, S. Priori, M. Oliveira, ARCH AGRON SOIL SCI, 64(3), 409-418, (2017).

4. A. Bonfante, A. Agrillo, R. Albrizio, A. Basile, R. Buonomo, R. De Mascellis, R., ... \& P. Manna, SOIL, 1, 427-441, (2015).

5. M.C. Ramos, G.V. Jones, J. Yuste, EUR J AGRON, 70, 57-70 (2015).

6. Bramley R.G.V, PROCEEDINGS OF 16TH AUSTRALIAN WINE INDUSTRY TECHNICAL CONFERENCE, (2016), 45-51.

7. A. Deloire A., E. Vaudour, V.A. Carey, V. Bonnardot, C. Van Leeuwen, J. INT. SCI. VIGNE VIN, 39(4), 149-162, (2005).

8. J.D. McNeill, Geonics EM38 Ground Conductivity Meter: EM38 Operating Manual, Geonics Limited, Ontario, Canada, (1990).

9. F.M Van Egmond, E.H Loonstra, J. Limburg. $1^{\text {st }}$ Global workshop on High Resolution Digital Soil Sensing \& Mapping, Sydney, Australia, (2008).

10. S. Priori, R. Barbetti, G. L'Abate, P. Bucelli, P. Storchi, E.A.C. Costantini, J MAPS, 10(3), 466-477, (2014).

11. G. Ricci Alunni, Proceedings of Italian conference "I Paesaggi del vino", Perugia, (2004).

12. B.S. Mpelasoka, D.P. Schachtman, M.T. Treeby, M.R. Thomas. A review of potassium nutrition in grapevines with special emphasis on berry accumulation. AUST J GRAPE WINE R, 9(3), 154168, (2003).

\section{Acknowledgements}

